\title{
Development of 4V-Class Bulk-Type All-Solid-State Lithium Rechargeable Batteries by a Combined Use of Complex Hydride and Sulfide Electrolytes for Room Temperature Operation $^{* 1}$
}

\author{
Atsushi Unemoto ${ }^{1, * 2}$, Genki Nogami ${ }^{2}$, Masaru Tazawa ${ }^{2}$, Mitsugu Taniguchi ${ }^{2}$ and Shin-ichi Orimo ${ }^{1,3}$ \\ ${ }^{1}$ WPI-Advanced Institute for Materials Research (WPI-AIMR), Tohoku University, Sendai 980-8577, Japan \\ ${ }^{2}$ Niigata Research Laboratory, Mitsubishi Gas Chemical Company, Inc., Niigata 950-3112, Japan \\ ${ }^{3}$ Institute for Materials Research, Tohoku University, Sendai 980-8577, Japan
}

We have operated a $4 \mathrm{~V}$-class bulk-type, all-solid-state $\mathrm{LiCoO}_{2} / \mathrm{Li}$ battery at room temperature. The battery consisted of a $\mathrm{Li}_{4}\left(\mathrm{BH}_{4}\right)_{3} \mathrm{I}$

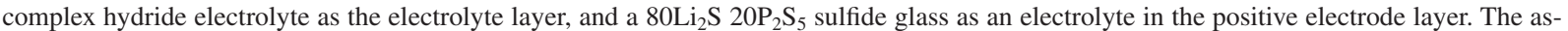
sembled battery exhibited a $92 \mathrm{mAh} \mathrm{g}^{-1}$ initial discharge capacity at $298 \mathrm{~K}$ and $0.1 \mathrm{C}$. The discharge capacity for the $20^{\text {th }}$ cycle remained as high as $83 \mathrm{mAh} \mathrm{g}^{-1}$, corresponding to a capacity retention ratio of nearly 90\%. [doi:10.2320/matertrans.M2017022]

(Received February 7, 2017; Accepted April 10, 2017; Published May 26, 2017)

Keywords: complex hydride electrolyte, sulfide electrolyte, bulk-type, all-solid-state battery, room temperature operation

\section{Introduction}

Complex hydrides possess energy storage and conversion-related functions, including hydrogen storage, ${ }^{1,2)}$ lithium storage, ${ }^{3,4)}$ and fast ionic conductions. ${ }^{5-7)} \mathrm{LiBH}_{4}$, a typical complex hydride, experiences a phase transition from an orthorhombic structure (low-temperature phase, LT phase) to a hexagonal structure (high-temperature phase, HT phase) at elevated temperatures and around $390 \mathrm{~K}^{8}{ }^{8}$ At this point, a high lithium-ionic conductivity that exceeds $\log \left(\sigma / \mathrm{S} \mathrm{cm}^{-1}\right)=$ -3 is realized in the HT phase of $\mathrm{LiBH}_{4},{ }^{5)}$ as shown in Fig. 1. The use of a complex hydride electrolyte for a battery assembly provides the following advantages: 1) use of materials that have a low gravimetric density (typically $1 \mathrm{~g} \mathrm{~cm}^{-3}$ ) is possible since light elements are chosen as constituents; 2) the transport number of lithium ions is close to unity since the materials are classified as electronic insulators; 3) complex hydrides allow for the establishment of a stable interface with a highly reactive metallic lithium electrode, which has the lowest voltage amongst the existing negative electrodes; 4) complex hydrides have high temperature durability since hydrogens in a crystal lattice are highly stabilized by a strong covalent bonding with center elements in a complex anion. The pyrolysis of complex hydrides is unlikely to occur in the temperature range considered for the battery operation; 6) the highly deformable nature of the complex hydrides allows for the preparation of an electrolyte compact merely by uniaxial pressing at room temperature, namely cold pressing. Introducing a robust interface between an electrode and an electrolyte is also easily performed by cold pressing. ${ }^{5-7)}$

In recent years, research and development efforts have been devoted to assembling bulk-type all-solid-state lithium rechargeable batteries that use complex hydride electrolytes,

\footnotetext{
${ }^{* 1}$ This Paper was Originally Published in Japanese in J. Japan Inst. Met Mater. 80 (2016) 720-725.

${ }^{* 2}$ Corresponding author, E-mail: unemoto@imr.tohoku.ac.jp. Present address: Research \& Development Group, Hitachi, Ltd., Hitachi 319-1292, Japan
}

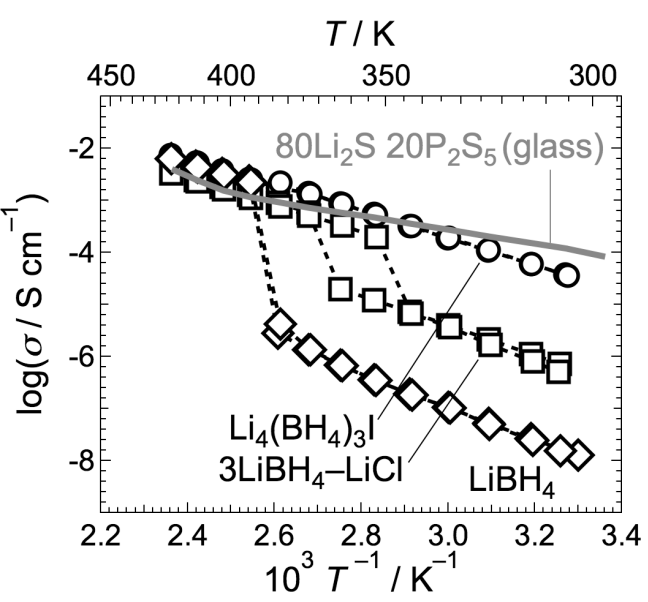

Fig. 1 Lithium-ionic conductivities as a function of inverse temperature: $\mathrm{LiBH}_{4}{ }^{5)}, \mathrm{Li}_{4}\left(\mathrm{BH}_{4}\right)_{3} \mathrm{I}^{14)}, 3 \mathrm{LiBH}_{4}-\mathrm{LiCl}^{14)}$, and $80 \mathrm{Li}_{2} \mathrm{~S} 20 \mathrm{P}_{2} \mathrm{~S}_{5}$ (glass).

including the HT phase of $\mathrm{LiBH}_{4}$. $\mathrm{LiBH}_{4}$ has high reducing ability; this material is used as a reducing agent in chemical synthesis. For this reason, $\mathrm{LiBH}_{4}$ can form a stable interface with a highly reactive and low voltage lithium electrode. ${ }^{5-7)}$ This high reducing ability of $\mathrm{LiBH}_{4}$ facilitates the reductive decomposition of positive electrodes, such as $\mathrm{LiCoO}_{2}$, which have oxidizing ability and high voltage, and thereby interferes with stable battery operation. To solve this issue, Takahashi and co-workers introduced an oxide-based solid electrolyte as a protection layer of a few tens of nanometers. This layer included $\mathrm{Li}_{3} \mathrm{PO}_{4}$ and avoided direct contact between the $\mathrm{LiBH}_{4}$ electrolyte and $\mathrm{LiCoO}_{2}$. As a result, repeated operation of the battery was successfully demonstrated..$^{9,10)}$ On the other hand, considering the high reducing ability of the complex hydride electrolyte, our research group has proposed a battery design principles that uses positive electrodes with a lower voltage and high capacity electrodes including $\operatorname{TiS}_{2}{ }^{7,11}$ ) and elemental sulfur, ${ }^{12,13)}$ combined with a lithium negative electrode. Repeated operation of the batteries based on this design concept has also been successfully demonstrated.

The operating temperature of a battery that uses the $\mathrm{LiBH}_{4}$ 
solid electrolyte is limited at temperatures higher than $390 \mathrm{~K}$ since the fast lithium-ionic conductivity of $\mathrm{LiBH}_{4}$ is realized in this temperature region. ${ }^{8)}$ Hence, the developments of complex hydride-based solid electrolytes and battery design principles that allow for repeated operation of the all-solidstate battery across a wide-temperature range, including room temperature, is urgently required. Maekawa and co-workers revealed that the $\mathrm{HT}$ phase of $\mathrm{LiBH}_{4}$ is stabilized at reduced temperatures by the doping lithium halides such as $\mathrm{LiCl}$, $\mathrm{LiBr}$, and LiI. For instance, $\mathrm{Li}_{4}\left(\mathrm{BH}_{4}\right)_{3} \mathrm{I}$ produces a high lithium-ionic conductivity of $\log \left(\sigma / \mathrm{S} \mathrm{cm}^{-1}\right)=-4.7$ at $300 \mathrm{~K}$, as shown in Fig. 1. ${ }^{14)}$ Sveinbjörnsson and co-workers assembled an all-solid-state battery that uses a $\mathrm{Li}_{4} \mathrm{Ti}_{5} \mathrm{O}_{12}$ porous thinfilm electrode, a $\mathrm{Li}_{13 / 16}\left(\mathrm{BH}_{4}\right)_{13 / 16} \mathrm{I}_{3 / 16}$ solid electrolyte, and a lithium negative electrode. They demonstrated repeated operation at $333 \mathrm{~K}^{15)}$ Yoshida and co-workers assembled a battery that uses a composite electrode containing a $\mathrm{Li}_{4}\left(\mathrm{BH}_{4}\right)_{3} \mathrm{I}$ solid-electrolyte and a $\mathrm{Li}_{4} \mathrm{Ti}_{5} \mathrm{O}_{12}$ active material in an electrode layer. Battery operation across a wide-temperature range, i.e., $296 \mathrm{~K}$ to $423 \mathrm{~K}$, was successfully demonstrated. ${ }^{16)}$ An appropriate battery design principle that properly considers the electrochemical stability of an electrolyte would allow us to assemble all-solid-state batteries suitable for a room temperature operation.

As a typical sulfide-based solid electrolyte, a $\mathrm{Li}_{2} \mathrm{~S}$ and $\mathrm{P}_{2} \mathrm{~S}_{5}$ glass electrolyte is known to exhibit a high lithium-ionic conductivity (for instance, a $80 \mathrm{Li}_{2} \mathrm{~S} 20 \mathrm{P}_{2} \mathrm{~S}_{5}$ glass electrolyte having a room temperature lithium-ionic conductivity of $\log (\sigma / \mathrm{S}$ $\left.\mathrm{cm}^{-1}\right)=-3.8$, and an activation energy of $\left.34 \mathrm{~kJ} \mathrm{~mol}^{-1}\right)^{17)}$. Owing to its highly deformable nature, this material allows for the assembly of a bulk-type all-solid-state battery merely by cold pressing. Repeated operation of a bulk-type all-solidstate battery that uses $4 \mathrm{~V}$-class $\mathrm{LiCoO}_{2}$ positive electrolyte at room temperature has been demonstrated. ${ }^{18)}$ At the interface, which is comprised of a sulfide-based solid electrolyte and $\mathrm{LiCoO}_{2}$, high interface resistance is attributed to the formation of a space charge layer. ${ }^{19-22)}$ In addition, with repeatd battery operation, a resistive layer is formed due to the mutual diffusion of constituent elements across the electrode and electrolyte interface. ${ }^{23)}$ These issues are solved by coating solid electrolytes, including $\mathrm{LiNbO}_{3}$, at the $\mathrm{LiCoO}_{2}$ surface.

In this study, we assembled a 4V-class bulk-type all-solidstate lithium rechargeable battery that allows for room temperature operation. Considering the literature described above, both complex hydride and sulfide electrolytes are used for a battery assembly. A positive electrode active material, $\mathrm{LiCoO}_{2}$, whose surface was coated by $\mathrm{LiNbO}_{3}$ to a $20 \mathrm{~nm}$ thickness, and a lithium negative electrode are used. In the positive electrode layer, a mixture of the $80 \mathrm{Li}_{2} \mathrm{~S} 20 \mathrm{P}_{2} \mathrm{~S}_{5}$ solid electrolyte and the $\mathrm{LiNbO}_{3}$-coated $\mathrm{LiCoO}_{2}$ active material was used, while $\mathrm{Li}_{4}\left(\mathrm{BH}_{4}\right)_{3} \mathrm{I}$ was employed as an electrolyte layer. Battery performance was evaluated at room temperature.

\section{Experimental Procedure}

$\mathrm{A} \mathrm{Li}_{4}\left(\mathrm{BH}_{4}\right)_{3} \mathrm{I}$ electrolyte was synthesized via a mechanical ball milling technique and subsequent annealing. ${ }^{14)}$ Powders of $\mathrm{LiBH}_{4}(\geq 90 \%$, Sigma-Aldrich) and LiI (99.999\%, Sigma-Aldrich) were used as starting materials. These powders were mixed using an agate pestle and mortal before the mixture was transferred to a $45 \mathrm{~mL}$ pot with 20 balls of $7 \mathrm{~mm}$ diameter. Mechanical ball milling was carried out at a rotation rate of $400 \mathrm{rpm}$ for $5 \mathrm{~h}$. From the resultant powder, no peaks other than the HT phase of $\mathrm{LiBH}_{4}$ appeared in the X-ray diffraction (XRD, X'pert PRO, PANalytical) patterns, and Raman spectra (Nicolet Almega XR, Thermo Fisher Scientific, Inc.). ${ }^{8)}$

To examine the oxidative stability of $\mathrm{Li}_{4}\left(\mathrm{BH}_{4}\right)_{3} \mathrm{I}$, a bulktype all-solid-state lithium battery using a $\mathrm{TiS}_{2}$ positive electrode, the lithium negative electrode, and the $\mathrm{Li}_{4}\left(\mathrm{BH}_{4}\right)_{3} \mathrm{I}$ electrolyte was assembled. Recently, the authors demonstrated repeated operation of over 300 cycles for a bulk-type all-solid-state lithium battery using the $\mathrm{TiS}_{2}$ positive electrode, the lithium negative electrode, and a $\mathrm{LiBH}_{4}$ electrolyte at $393 \mathrm{~K}^{11)}$ Hence, we consider that a similar battery configuration is appropriate for investigating the manner by which iodide-ions in the solid electrolyte affect the stability of the $\mathrm{LiBH}_{4}$ electrolyte and battery performance. In addition to this comparison, we also assembled a battery that uses a $\mathrm{LiBH}_{4}$ electrolyte instead of $\mathrm{Li}_{4}\left(\mathrm{BH}_{4}\right)_{3} \mathrm{I}$ in the composite positive electrode, with which $\mathrm{Li}_{4}\left(\mathrm{BH}_{4}\right)_{3} \mathrm{I}$ was used for the electrolyte layer.

$\mathrm{TiS}_{2}$, and $\mathrm{Li}_{4}\left(\mathrm{BH}_{4}\right)_{3} \mathrm{I}$ or $\mathrm{LiBH}_{4}$, were weighted out to a 40:60 weight ratio and then mixed in an agate pestle and mortar. The resultant powders were used for the composite positive electrodes. The powders, $25 \mathrm{mg} \mathrm{Li}{ }_{4}\left(\mathrm{BH}_{4}\right)_{3} \mathrm{I}$ or $20 \mathrm{mg}$ $\mathrm{LiBH}_{4}$, were transferred into an $8 \mathrm{~mm}$ diameter die and uniaxially pressed at $60 \mathrm{MPa}$. Subsequently, $6 \mathrm{mg}$ composite positive electrodes were placed on the solid-electrolyte pellet still present in the die and further pressed at $240 \mathrm{MPa}$ to produce a robust interface between the positive electrode and electrolyte layers. A lithium foil for use as a negative electrode was placed on the opposite side of the composite positive electrode layer. Battery tests were carried out at $393 \mathrm{~K}$ with a discharge-charge rate of $0.05 \mathrm{C}$ (corresponding to a current density of $57 \mu \mathrm{A} \mathrm{cm} \mathrm{cm}^{-2}, 580$ Battery Test System, Scribner Associates Inc.). The appearance of our battery and the configuration of the electrochemical system appeared have been given elsewhere. ${ }^{11-13)}$

For microstructure observation and element distribution analysis, a cross-section of the composite positive electrode was produced by a focused ion beam (FIB, FB2200, Hitachi High-Technologies Corp.) with Ga-ion beam radiation. For this purpose, a field-emission scanning electron microscopy (FE-SEM, SU9000, Hitachi High-Technologies Corp.) and an energy dispersive X-ray (EDX, Apollo XLT, Ametek, Inc.) were employed.

An $80 \mathrm{Li}_{2} \mathrm{~S} 20 \mathrm{P}_{2} \mathrm{~S}_{5}$ glass electrolyte was synthesized by the mechanical ball milling technique, as reported in a preceding paper. ${ }^{23)}$ Powders of $\mathrm{Li}_{2} \mathrm{~S}$ (98\%, Sigma-Aldrich) and $\mathrm{P}_{2} \mathrm{~S}_{5}$ (99\%, Sigma-Aldrich) were mixed using an agate pestle and mortar. The resultant mixed powders were then transferred into a $45 \mathrm{~mL}$ zirconia pot with 160 zirconia balls of a $5 \mathrm{~mm}$ diameter. The mechanical milling was carried out at a rotation rate of $510 \mathrm{rpm}$ for $10 \mathrm{~h}$. Only a hollow pattern appeared in the XRD patterns of the resultant powders after mechanical ball milling; hence, we consider that glass electrolyte was obtained. The ionic conductivity of the prepared glass electrolyte compact was measured by a two-probe ac technique 
(3520-80 Chemical Impedance Meter, Hioki Corp.) in the temperature range of 298-423 K.

$\mathrm{LiNbO}_{3}$ was coated on to the surface of the $\mathrm{LiCoO}_{2}$ particles using a rolling fluidized coating machine (MP-01, Powrex Corp. $)^{19,20)}$ (this product is hereafter referred to as "LiN$\mathrm{bO}_{3}$-coated $\mathrm{LiCoO}_{2}$ "). The powders of $\mathrm{LiNbO}_{3}$-coated $\mathrm{Li}$ $\mathrm{CoO}_{2}$, a Ketjen Black (KB) conductive additive, and the $80 \mathrm{Li}_{2} \mathrm{~S} 20 \mathrm{P}_{2} \mathrm{~S}_{5}$ glass electrolyte were weighed out to a 40:60:6 weight ratio, before being mixed and used for a composite positive electrode. $\mathrm{Li}_{4}\left(\mathrm{BH}_{4}\right)_{3} \mathrm{I}$ electrolyte powder $(101.1 \mathrm{mg})$ was transferred to a $10-\mathrm{mm}$-diameter die and then uniaxially pressed at $20 \mathrm{MPa}$ and room temperature. Subsequently, $11.5 \mathrm{mg}$ of composite positive electrode powder was placed on the electrolyte compact that was still present in the die, before being further pressed at $240 \mathrm{MPa}$. As a negative electrode, lithium foil was placed on the opposite side of the composite positive electrode. The battery test was carried out at $297 \mathrm{~K}$ and a charge-discharge rate of $0.1 \mathrm{C}$, corresponding to a current density of $73 \mu \mathrm{A} \mathrm{cm} \mathrm{cm}^{-2}$, using an electroanalytical system, VMP3 (Bio-Logic Science Instruments). Microstructure observation by FE-SEM and element distribution analysis by EDX were carried out for the compact, which was comprised of the $\mathrm{LiNbO}_{3}$-coated $\mathrm{LiCoO}_{2}, \mathrm{~KB}$, and $\mathrm{Li}_{4}\left(\mathrm{BH}_{4}\right)_{3} \mathrm{I}$, to evaluate the thickness of the $\mathrm{LiNbO}_{3}$ layer at the $\mathrm{LiCoO}_{2}$ surface. A cross-section of this compact was produced by the FIB with Ga-ion beam radiation.

\section{Results and Discussions}

Despite the use of only cold pressing, a robust interface was introduced between the $\mathrm{TiS}_{2}$ active material and the $\mathrm{Li}_{4}\left(\mathrm{BH}_{4}\right)_{3} \mathrm{I}$ electrolyte, as shown by the cross-sectional FESEM image, and by the iodine, titanium, and sulfur distributions of the composite positive electrode before the battery test (Fig. 2 (a)-(d)). Such an interface is expected to allow for a smooth charge transfer reaction during battery operation. This microstructure is similar to that of the composite positive electrode comprised of $\mathrm{TiS}_{2}$ and $\mathrm{LiBH}_{4}{ }^{7,11)}$ This suggests that high deformability is still maintained in the iodide-ion containing complex hydride, $\mathrm{Li}_{4}\left(\mathrm{BH}_{4}\right)_{3} \mathrm{I}$.

Battery reaction between $\mathrm{TiS}_{2}$ and lithium ions proceeds via the following electrochemical reaction, ${ }^{24,25)}$

$$
\mathrm{TiS}_{2}+x \mathrm{Li}^{+}+x \mathrm{e}^{-} \rightleftarrows \mathrm{Li}_{x} \mathrm{TiS}_{2}
$$

The reactions toward the right and left represent discharge and charge reactions, respectively. The theoretical capacity is $239 \mathrm{mAh} \mathrm{g}^{-1}$ when the variation of $x$ in $\mathrm{Li}_{x} \mathrm{TiS}_{2}$ is assumed to be in the range of $0-1$. Figure 3 (a) shows discharge-charge profiles of a bulk-type all-solid-state $\mathrm{TiS}_{2} / \mathrm{Li}_{4}\left(\mathrm{BH}_{4}\right)_{3} \mathrm{I}$ । $\mathrm{Li}_{4}\left(\mathrm{BH}_{4}\right)_{3} \mathrm{I} \mid \mathrm{Li}$ battery. The initial discharge capacity was $49 \mathrm{mAh} \mathrm{g}^{-1}$, whereas the second was $141 \mathrm{mAh} \mathrm{g}^{-1}$. A lower initial discharge capacity compared to the second one is considered to be due to a solid-state reaction between $\mathrm{TiS}_{2}$ and $\mathrm{Li}_{4}\left(\mathrm{BH}_{4}\right)_{3} \mathrm{I}$ to form $\mathrm{Li}_{x} \mathrm{TiS}_{2}$, corresponding to a self-discharge
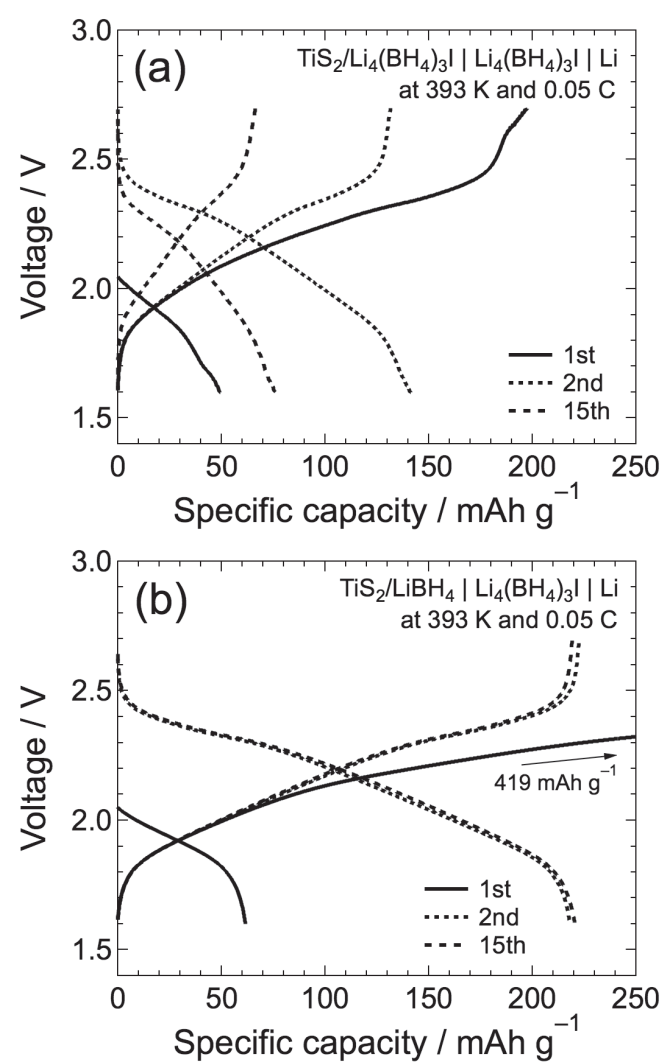

Fig. 3 Performance of the bulk-type all-solid-state batteries operated at $393 \mathrm{~K}$ and $0.05 \mathrm{C}$ : (a) $\mathrm{TiS}_{2} / \mathrm{Li}_{4}\left(\mathrm{BH}_{4}\right)_{3} \mathrm{I}\left|\mathrm{Li}_{4}\left(\mathrm{BH}_{4}\right)_{3} \mathrm{I}\right| \mathrm{Li}$, and (b) $\mathrm{TiS}_{2} /$ $\mathrm{LiBH}_{4}\left|\mathrm{Li}_{4}\left(\mathrm{BH}_{4}\right)_{3} \mathrm{I}\right| \mathrm{Li}$
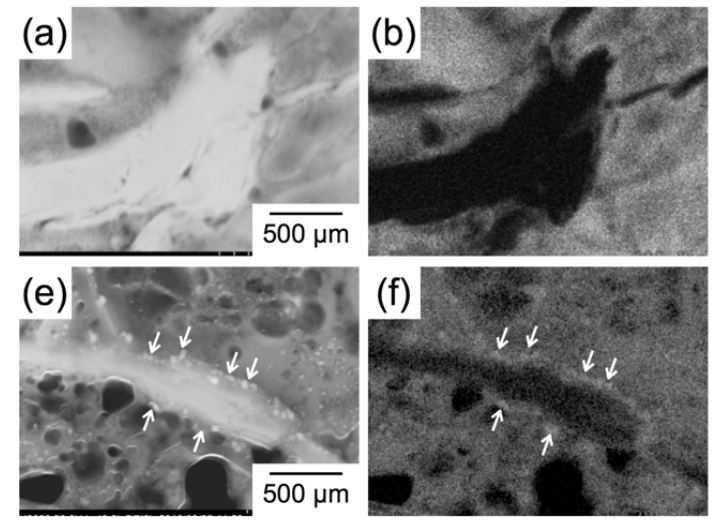
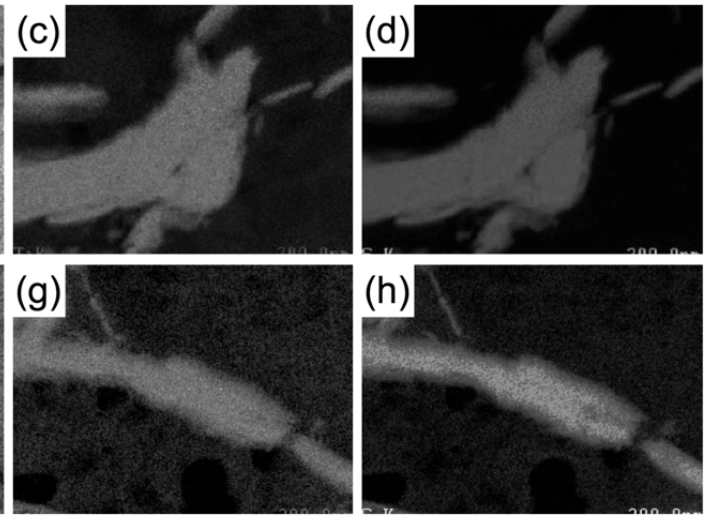

Fig. 2 Microstructure and element distributions of the composite positive electrode layer, $\mathrm{TiS}_{2} / \mathrm{Li}_{4}\left(\mathrm{BH}_{4}\right)_{3} \mathrm{I}$. Before the battery test: (a) cross-sectional FESEM image, and distributions of (b) I, (c) Ti, and (d) S. After the battery test: (e) cross-sectional FE-SEM image, and distributions of (f) I, (g) Ti, and (h) S. 
reaction, at a battery operating temperature of $393 \mathrm{~K}$ before the battery test. ${ }^{7,11)}$ Gradual capacity decrease then occurred with repeated battery operation, and the $15^{\text {th }}$ discharge capacity became $76 \mathrm{mAh} \mathrm{g}^{-1}$. The voltage drop caused by the internal resistance increase became marked as the cycle number increased; thereby, discharge capacities were reduced.

To further examine how the iodide-ion in $\mathrm{Li}_{4}\left(\mathrm{BH}_{4}\right)_{3} \mathrm{I}$ in the composite positive electrode affected battery performance at $393 \mathrm{~K}$, we assembled a battery that used a $\mathrm{LiBH}_{4}$ solid electrolyte in the composite positive electrode, while $\mathrm{Li}_{4}\left(\mathrm{BH}_{4}\right)_{3} \mathrm{I}$ was used for the electrolyte layer. For the battery configuration that used $\mathrm{LiBH}_{4}$ in the composite positive electrode, the initial discharge capacity was only $61 \mathrm{mAh} \mathrm{g}^{-1}$; this was due to the solid-state reaction between $\mathrm{TiS}_{2}$ and $\mathrm{LiBH}_{4}$ to form $\mathrm{Li}_{x} \mathrm{TiS}_{2}$ (self-discharge). The second discharge capacity recovered to $218 \mathrm{mAh} \mathrm{g}^{-1}$, which is close to the theoretical capacity of $\mathrm{TiS}_{2}\left(239 \mathrm{mAh} \mathrm{g}^{-1}\right)$. The initial charge capacity was $419 \mathrm{mAh} \mathrm{g}^{-1}$, which exceeded the theoretical capacity. This is due to the oxidative decomposition of unreacted $\mathrm{LiBH}_{4}$ of the self-discharge reaction before initial charge between $\mathrm{TiS}_{2}$ and $\mathrm{LiBH}_{4}$. This battery did not show any marked capacity reduction with repeated battery operation. Indeed, the $15^{\text {th }}$ discharge capacity remained as high as $220 \mathrm{mAh} \mathrm{g}^{-1}$. This result suggests that the capacity fading of the bulk-type allsolid-state $\mathrm{TiS}_{2} / \mathrm{Li}_{4}\left(\mathrm{BH}_{4}\right)_{3} \mathrm{I}\left|\mathrm{Li}_{4}\left(\mathrm{BH}_{4}\right)_{3} \mathrm{I}\right| \mathrm{Li}$ battery, seen in Fig. 3 (a), is essentially attributable to interface instability between the TiS 2 positive electrode and the $\mathrm{Li}_{4}\left(\mathrm{BH}_{4}\right)_{3} \mathrm{I}$ solid electrolyte.

Microstructure observation and element distribution analysis of the composite positive electrode were carried out after the battery test to investigate how repeated battery operation affects the interface stability between $\mathrm{TiS}_{2}$ and $\mathrm{Li}_{4}\left(\mathrm{BH}_{4}\right)_{3} \mathrm{I}$. Figure 2 (e) shows a cross-sectional FE-SEM image of the positive electrode layer after the battery test, (f)-(h) show the distributions of iodine, titanium, and sulfur, respectively. After the battery test, iodine was concentrated at the interface between $\mathrm{TiS}_{2}$ and $\mathrm{Li}_{4}\left(\mathrm{BH}_{4}\right)_{3} \mathrm{I}$. The voltage drop became large with repeated battery operation, as the discharge-charge profiles shown in Fig. 3 (a). This suggests that the concentration of iodine was increased by the decomposition of $\mathrm{Li}_{4}\left(\mathrm{BH}_{4}\right)_{3} \mathrm{I}$ due to the solid-state reaction with $\mathrm{TiS}_{2}$, resulting in the formation and precipitation of iodine-containing compounds and an increase in resistance. Hence, to realize repeated battery operation with low interface resistivity and high capacity, the use of a solid electrolyte that hinders such a side reaction (i.e., that leads to the precipitation and formation of iodine-containing species) would be beneficial.

Assembling an all-solid-state battery based on a sulfide-based solid electrolyte, and which has a lower internal resistance and allows for repeated battery operation, is possible when a $4 \mathrm{~V}$-class $\mathrm{LiCoO}_{2}$ electrode surface is coated by a solid electrolyte. ${ }^{19-23)}$ Figure 4 (a) and (b) shows cross-sectional FE-SEM images of the composite comprised of LiN$\mathrm{bO}_{3}$-coated $\mathrm{LiCoO}_{2}, \mathrm{~KB}$, and $\mathrm{Li}_{4}\left(\mathrm{BH}_{4}\right)_{3} \mathrm{I}$. The distributions of cobalt, niobium, carbon, and iodine are shown in Fig. 4 (c)(f). From these results, it is observed that $\mathrm{LiCoO}_{2}$ particles were homogeneously coated by $\mathrm{LiNbO}_{3}$ with a 20 nm thickness.

The lithium-ionic conductivity of the $80 \mathrm{Li}_{2} \mathrm{~S} 20 \mathrm{P}_{2} \mathrm{~S}_{5}$ glass electrolyte synthesized in this study is shown in Fig. 1. The lithium-ionic conductivity at $298 \mathrm{~K}$ and activation energy were $\log \left(\sigma / \mathrm{S} \mathrm{cm}^{-1}\right)=-4.0$ and $29 \mathrm{~kJ} \mathrm{~mol}^{-1}$, respectively. These values relatively well with the values in the preceding work. ${ }^{17)}$

Electrochemical reaction of $\mathrm{LiCoO}_{2}$ proceeds as, ${ }^{26)}$

$$
\mathrm{LiCoO}_{2} \rightleftarrows \mathrm{Li}_{1-x} \mathrm{CoO}_{2}+x \mathrm{Li}^{+}+x \mathrm{e}^{-}
$$

The reactions toward right and left represent charge and discharge reactions, respectively. When the upper voltage limitation is set to $4.2 \mathrm{~V}, x$ in $\mathrm{Li}_{1-x} \mathrm{CoO}_{2}$ varies in the range of $0-0.5$, corresponding to a specific capacity of $137 \mathrm{mAh} \mathrm{g}^{-1}$. Chargedischarge profiles of our 4V-class bulk-type all-solid-state lithium battery operated at $298 \mathrm{~K}$ are shown in Fig. 5 (a). Discharge capacity and coulombic efficiency as a function of cycle number are shown in Fig. 5 (b). As we expected, our battery realized $4 \mathrm{~V}$ operation. Voltage plateaus appeared at $4.05 \mathrm{~V}$ and $3.8 \mathrm{~V}$ for charge and discharge, respectively. The initial discharge capacity was as high as $92 \mathrm{mAh} \mathrm{g}^{-1}$. Our battery cycled without marked capacity fading. The $20^{\text {th }}$ discharge capacity remained as high as $83 \mathrm{mAh} \mathrm{g}^{-1}$, corresponding to a discharge capacity retention ration of $90 \%$. Although the coulombic efficiency (ratio of discharge capacity to charge capacity) was $75 \%$, it recovered to $97-100 \%$ from the $2^{\text {nd }}$ cycle. This suggests that marked side reaction was unlikely to proceed during repeated battery operation.

In this study, we figured out that repeated battery operation is possible by a combined use of solid electrolytes, having different electrochemical stabilities, although the sole use of an electrolyte does not realize the repeated battery operation. Similar to this battery configuration, Kawaji and co-workers recently realized the operation of a high-temperature durable
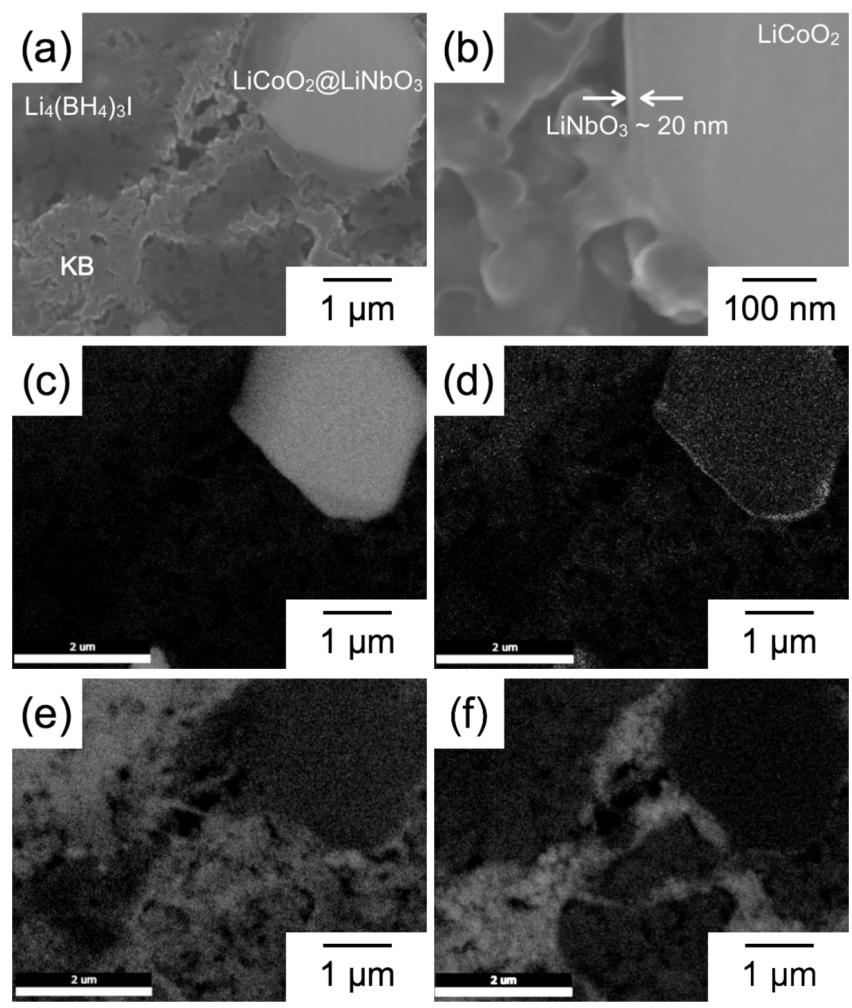

Fig. 4 Microstructure of $\mathrm{LiNbO}_{3}$-coated $\mathrm{LiCoO}_{2}$ in the $\mathrm{Li}_{4}\left(\mathrm{BH}_{4}\right)_{3} \mathrm{I}, \mathrm{KB}$ and $\mathrm{LiNbO}_{3}$-coated $\mathrm{LiCoO}_{3}$ compact: (a) and (b) cross-sectional FESEM image, and distributions of (c) $\mathrm{Co}$, (d) Nb, (e) C, and (f) I. 

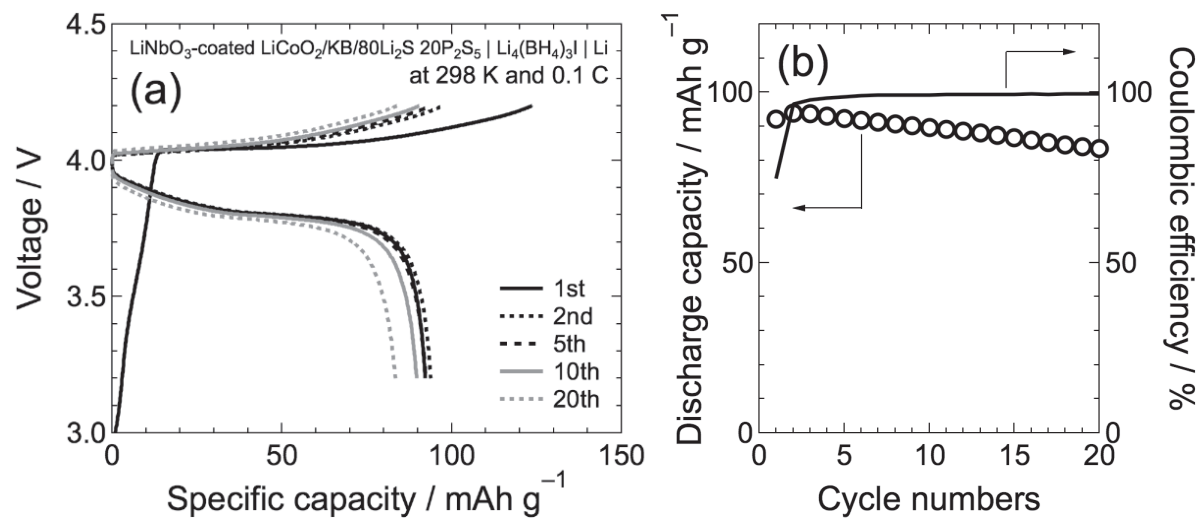

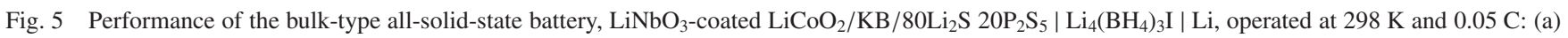
typical charge-discharge profiles, and (b) cycle performance.

and sulfur-free $4 \mathrm{~V}$-class bulk-type all-solid-state battery by the combined use of a complex hydride electrolyte and an oxide electrolyte. ${ }^{27)}$ A major remaining issue is achieving improved battery performance, including high capacity and low internal resistance, by further increasing the lithium-ionic conductivity of the complex hydride electrolyte at reduced temperatures, i.e., near to, or lower than, room temperature.

Recently, a solid electrolyte in which $\mathrm{LiBH}_{4}$ was dispersed in a $\mathrm{Li}_{2} \mathrm{~S}-\mathrm{P}_{2} \mathrm{~S}_{5}$ glass matrix, realized a high lithium-ionic conductivity of $\log \left(\sigma / \mathrm{S} \mathrm{cm}^{-1}\right)=-2.8$ at $298 \mathrm{~K}^{28)}$ In addition, the crystalline phase of $90 \mathrm{LiBH}_{4}-10 \mathrm{P}_{2} \mathrm{~S}_{5}$, with a nominal composition, exhibited a lithium-ionic conductivity of $\log (\sigma / \mathrm{S}$ $\left.\mathrm{cm}^{-1}\right)=-3.0$ at $300 \mathrm{~K}^{29}{ }^{29}$ These materials do not include a phase transition, as seen in $\mathrm{LiBH}_{4}$, at least above room temperature; hence, the assembly of batteries that allowed for room temperature operation was possible. In other reports, high lithium ${ }^{30-33)}$ and sodium ${ }^{30,32-35)}$ ionic conductivities in complex hydrides containing cage-like cluster-anions, including $\left[\mathrm{B}_{12} \mathrm{H}_{12}\right]^{2-}$ and $\left[\mathrm{CB}_{11} \mathrm{H}_{12}\right]^{-}$, have been discovered. Repeated battery operation of all-solid-state batteries by using some of the above materials has been successfully demonstrated. ${ }^{31,32)}$ In complex hydride solid electrolytes, the cation transport rate is closely related to the reorientational dynamics of the complex anions, containing hydrogen. ${ }^{6,7,36-38)}$ On the basis of this knowledge, diversification of the complex hydride electrolyte has rapidly progressed with regards to crystal structure and composition. To achieve better performance of bulk-type all-solid-state batteries, further exploration of this new-type of complex hydride solid electrolyte is highly desirable.

\section{Conclusion}

In this study, we assembled a 4V-class bulk-type all-solidstate lithium rechargeable battery by hybrid use of complex hydride and sulfide electrolytes. Repeated operation of this battery was successfully demonstrated at room temperature. For use as the lithium metal negative electrode, we chose $\mathrm{Li}_{4}\left(\mathrm{BH}_{4}\right)_{3} \mathrm{I}$ electrolyte, which has a high reducing ability. A mixture of a $\mathrm{LiCoO}_{2}$ active material, whose surface was covered by $\mathrm{LiNbO}_{3}$ with a 20 -nm thickness, a $80 \mathrm{Li}_{2} \mathrm{~S} 20 \mathrm{P}_{2} \mathrm{~S}_{5}$ glass solid electrolyte, and a $\mathrm{KB}$ conductive additive was used for the composite positive electrode. Our battery al- lowed for repeated operation at $298 \mathrm{~K}$ and a charge-discharge rate of $0.1 \mathrm{C}$. The initial and $20^{\text {th }}$ discharge capacities of our battery were $92 \mathrm{mAh} \mathrm{g}^{-1}$ and $83 \mathrm{mAh} \mathrm{g}^{-1}$, respectively, and the capacity retention ratio was as high as $90 \%$. This suggests that our battery design allows for stable battery operation at reduced temperature, e.g., $298 \mathrm{~K}$.

\section{Acknowledgments}

The authors would like to thank Mr. K. Sato, Ms. H. Ohmiya, and Ms. N. Warifune for technical assistances. Financial supports from the Target Project 4 of WPI-AIMR, Tohoku University; Collaborative Research Center on Energy Materials, Tohoku University; JSPS KAKENHI Grant No. 25220911; and the Advanced Low Carbon Technology Research and Development Program (ALCA) from the Japan Science and Technology Agency (JST) are gratefully acknowledged.

\section{REFERENCES}

1) L. Schlapbach and A. Züttel: Nature 414 (2001) 353-358.

2) S. Orimo, Y. Nakamori, J.R. Eliseo, A. Züttel and C.M. Jensen: Chem. Rev. 107 (2007) 4111-4132.

3) W. Zaïdi, J.-P. Bonnet, J. Zhang, F. Cuevas, M. Latroche, S. Couillaiud, J.-L. Bobet, M.T. Sougrati, J.-C. Jumas and L. Aymard: Int. J. Hydrogen Energ. 38 (2013) 4798-4808.

4) J. Zhang, W. Zaïdi, V. Paul-Boncour, K. Provost, A. Michalowicz, F. Cuevas, M. Latroche, S. Belin, J.-P. Bonnet and L. Aymard: J. Mater. Chem. A Mater. Energy Sustain. 1 (2013) 4706-4717.

5) M. Matsuo, Y. Nakamori, S. Orimo, H. Maekawa and H. Takamura: Appl. Phys. Lett. 91 (2007) 224103.

6) M. Matsuo and S. Orimo: Adv. Energy Mater. 1 (2011) 161-172.

7) A. Unemoto, M. Matsuo and S. Orimo: Adv. Funct. Mater. 24 (2014) 2267-2279.

8) J.-P. Soulié, G. Renaudin, R. Cerny and K. Yvon: J. Alloy. Compd. 346 (2002) 200-205.

9) K. Takahashi, K. Hattori, T. Yamazaki, K. Takada, M. Matsuo, S. Orimo, H. Maekawa and J. Takamura: J. Power Sources 226 (2013) 61-64.

10) K. Takahashi, H. Maekawa and H. Takamura: Solid State Ionics 262 (2014) 179-182.

11) A. Unemoto, T. Ikeshoji, S. Yasaku, M. Matsuo, V. Stavila, T.J. Udovic and S. Orimo: Chem. Mater. 27 (2015) 5407-5416.

12) A. Unemoto, S. Yasaku, G. Nogami, M. Tazawa, M. Taniguchi, M. Matsuo, T. Ikeshoji and S. Orimo: Appl. Phys. Lett. 105 (2014) 083901.

13) A. Unemoto, C. Chen, Z. Wang, M. Matsuo, T. Ikeshoji and S. Orimo: Nanotechnology 26 (2015) 254001. 
14) H. Maekawa, M. Matsuo, H. Takamura, M. Ando, Y. Noda, T. Karahashi and S. Orimo: J. Am. Chem. Soc. 131 (2009) 894-895.

15) D. Sveinbjörnsson, A.S. Christiansen, R. Viskinde, P. Norby and T. Vegge: J. Electrochem. Soc. 161 (2014) A1432-A1439.

16) K. Yoshida, S. Suzuki, J. Kawaji, A. Unemoto and S. Orimo: Solid State Ionics 285 (2016) 96-100.

17) A. Hayashi, S. Hama, H. Morimoto, M. Tatsumisago and T. Minami: J. Am. Chem. Soc. 84 (2001) 477-479.

18) A. Sakuda, A. Hayashi and M. Tatsumisago: Chem. Mater. 22 (2010) 949-956.

19) N. Ohta, K. Takada, L. Zhang, R. Ma, M. Osada and T. Sasaki: Adv. Mater. 18 (2006) 2226-2229.

20) N. Ohta, K. Takada, I. Sakaguchi, L. Zhang, R. Ma, K. Fukuda, M. Osada and T. Sasaki: Electrochem. Commun. 9 (2007) 1486-1490.

21) K. Takada: Acta Mater. 61 (2013) 759-770.

22) J. Haruyama, K. Sodeyama, L. Han, K. Takada and Y. Tateyama: Chem. Mater. 26 (2014) 4248-4255.

23) A. Sakuda, A. Hayashi and M. Tatsumisago: Sci. Rep. 3 (2013) 2261.

24) M.S. Whittingham: Science 192 (1976) 1126-1127.

25) M.S. Whittingham: Prog. Solid State Chem. 12 (1978) 41-99.

26) T. Ohzuku and A. Ueda: J. Electrochem. Soc. 141 (1994) 2972-2977.

27) J. Kawaji, S. Suzuki, K. Yoshida, A. Unemoto, S. Orimo: Extended Abstracts of the $56^{\text {th }}$ Battery Symposium in Japan (2015) pp. 463.

28) A. Yamauchi, A. Sakuda, A. Hayashi and M. Tatsumisago: J. Power Sources 244 (2013) 707-710.

29) A. Unemoto, H. Wu, T.J. Udovic, M. Matsuo, T. Ikeshoji and S. Orimo:
Chem. Commun. (Camb.) 52 (2016) 564-566.

30) L. He, H.-W. Li, H. Nakajima, N. Tumanov, Y. Filinchuk, S.-J. Hwang, M. Sharma, H. Hageman and E. Akiba: Chem. Mater. 27 (2015) 54835486.

31) J.A. Teprovich, Jr., H. Colon-Mercado, A.L. Washington, II, P.A. Ward, S. Greenway, D.M. Missimer, H. Hartman, J. Velten, J.H. Christian and R. Zidan: J. Mater. Chem. A Mater. Energy Sustain. 3 (2015) 22853-22859.

32) W.S. Tang, A. Unemoto, W. Zhou, V. Stavila, M. Matsuo, H. Wu, S. Orimo and T.J. Udovic: Energy Environ. Sci. 8 (2015) 3637-3645.

33) W.S. Tang, M. Matsuo, H. Wu, V. Stavila, W. Zhou, A.A. Talin, A.V. Soloninin, R.V. Skoryunov, O.A. Babanova, A.V. Skripov, A. Unemoto, S. Orimo and T.J. Udovic: Adv. Energy Mater. 6 (2016) 1502237.

34) T.J. Udovic, M. Matsuo, A. Unemoto, N. Verdal, V. Stavila, A.V. Skripov, J.J. Rush, H. Takamura and S. Orimo: Chem. Commun. (Camb.) 50 (2014) 3750-3752.

35) T.J. Udovic, M. Matsuo, W.S. Tang, H. Wu, V. Stavila, A.V. Soloninin, R.V. Skryunov, O.A. Babanova, A.V. Skripov, J.J. Rush, A. Unemoto, H. Takamura and S. Orimo: Adv. Mater. 26 (2014) 7622-7626.

36) T. Ikeshoji, E. Tsuchida, K. Ikeda, M. Matsuo, H.-W. Li, Y. Kawazoe and S. Orimo: Appl. Phys. Lett. 95 (2009) 221901.

37) T. Ikeshoji, E. Tsuchida, T. Morishita, K. Ikeda, M. Matsuo, Y. Kawazoe and S. Orimo: Phys. Rev. B 83 (2011) 144301.

38) P. Martelli, A. Remhof, A. Borgschulte, R. Ackermann, T. Strässle, J.P. Embs, M. Ernst, M. Matsuo, S. Orimo and A. Züttel: J. Phys. Chem. A 115 (2011) 5329-5334. 